(C)American Mental Health Counselors Association, 2023. This paper is not the copy of record and may not exactly replicate the authoritative document published in the AMHCA journal. Please do not copy or cite without the publisher's permission. The final article is available, upon publication, at: $\underline{\text { https://doi.org/10.17744/mehc.45.1.05 }}$

\title{
Stereotyping Among Graduate Students in Mental Health Fields: An EEG Study
}

\author{
Wesley B. Webber ${ }^{1}$, Firat Soylu ${ }^{2}$, and Joy J. Burnham ${ }^{2}$ \\ ${ }^{1}$ Department of Addictions and Rehabilitation Studies, East Carolina University \\ ${ }^{2}$ Department of Educational Studies in Psychology, Research Methodology, and Counseling, \\ University of Alabama
}

\begin{abstract}
Author Note
Wesley B. Webber https://orcid.org/0000-0002-7348-8364

Firat Soylu https://orcid.org/0000-0003-0743-818X

Joy J. Burnham https://orcid.org/0000-0002-1619-9611

This project was supported by a grant from the Alabama Counseling Association. The authors wish to acknowledge the assistance of the members of the Embodied Learning Design and Educational Neuroscience Lab on this project.

Correspondence concerning this article should be addressed to Wesley B. Webber, Department of Addictions and Rehabilitation Studies, Mail Stop 677, East Carolina University, 1000 East $5^{\text {th }}$ Street, Greenville, NC 27858-4353. Email: webberw21@ecu.edu
\end{abstract}




\begin{abstract}
Counselors are obligated to work effectively with diverse groups, yet stereotyping and biases can impede counselors' efforts. Understanding implicit processes in social cognition among counselors is important because implicit stereotyping and biases can negatively influence counselors' work. Investigation of cognitive processes through electroencephalography (EEG) can illuminate implicit tendencies that potentially lead to microaggressions toward clients. In this study, we tested the hypothesis that graduate students in mental health fields would show indicators of stereotyping in a priming experiment that measured stereotyping implicitly. Both neural (N400 event-related potential component) and behavioral (reaction time) measures were used as indexes for stereotyping. The results showed neural and behavioral markers of stereotyping toward Black men and White women in a sample of graduate students in mental health fields composed of mostly White women. Implications for counseling practice and research are discussed.
\end{abstract}

Keywords: stereotyping, EEG, N400, social cognition, microaggressions 


\section{Stereotyping Among Graduate Students in Mental Health Fields: An EEG Study}

Counselors are required by their code of ethics (American Counseling Association, 2014) to establish productive therapeutic relationships with their clients and avoid imposing their own personal values onto them. However, social cognition (a variety of cognitive processes associated with "making sense" of others) can be influenced by stereotyping and biases in implicit ways (Fazio \& Olson, 2003; Macrae \& Bodenhausen, 2000). The present study utilized a neuroscience method to study implicit stereotyping in a sample of graduate students in mental health fields (primarily counselors-in-training). Specifically, we used the event-related potential (ERP) technique, which allows for the testing of hypotheses through analysis of electroencephalography (EEG) data recorded during experimental conditions.

\section{Measurement of Stereotyping and Biases}

The study of implicit stereotyping and biases is distinct from their study at explicit levels (Fazio \& Olson, 2003; Macrae \& Bodenhausen, 2000). Dual process theories of cognition describe how separable processes can contribute to cognition and have highlighted the role of both implicit (automatic) processes and controlled processes in social cognition. For example, according to the MODE (Motivation and Opportunity as Determinants) model, a person's motivation and opportunity to control responses affect responses in explicit measurement situations such as self-report surveys (Fazio \& Towles-Schwen, 1999). Through a dual process lens, the opportunity for controlled processing in self-report measurement allows for human tendencies toward socially desirable responding to obscure measurements of stereotyping and biases. In authentic social contexts (outside of such explicit measurement scenarios), implicit biases and stereotyping may unknowingly affect socioemotional processes and interpersonal interactions if they are not acknowledged and controlled (Dovidio et al., 1997; McConnell \& 
Leibold, 2001). For example, in a counseling session, the counselor's negative emotions (stemming from implicit biases) might unknowingly affect the counselor's conceptualization of the client, or the counselor might unknowingly apply stereotypes during their efforts to understand and empathize with the client.

Implicit social cognition can be studied through methods that remove participants' opportunity and motivation to control their measured responses (Fazio \& Olson, 2003). For implicit biases, this is often done through an Implicit Association Test (IAT; Greenwald et al., 1998). For example, in a race IAT assessing potential biases toward Black or White people, a participant responds to trials in which they indicate by a keyboard response whether presented target items reflect the concepts of good, bad, Black, or White. In one experimental block, "good" and "White" require the same keyboard response, while "bad" and "Black" require an alternative keyboard response. In a separate experimental block, "good" and "Black" require the same keyboard response, while "bad" and "White" require the alternative response. A participant whose reaction time (RT) is faster while classifying items as "good or White" or "bad or Black" (as compared to "good or Black" or "bad or White") would be said to show an implicit bias against Black people as compared to White. In this case, faster RT reflects stronger associations between good/White and bad/Black as compared to good/Black and bad/White. In other words, cognitive processing is facilitated (thereby increasing RT) when items requiring the same keyboard response are perceived as congruent rather than incongruent with one another.

Stereotyping tendencies can be distinguished from implicit biases in that implicit bias involves one's tendency to associate a particular group with either positive or negative valence ("good" or "bad"), while stereotyping of a particular group can involve both positive and negative associations (i.e., stereotypes of a particular group can be positive or negative in 
valence). Through priming experimental designs, participants' potential stereotypes toward specific groups can be assessed implicitly (Hehman et al., 2014; Wang et al., 2016; X. Zhang et al., 2016). Priming experimental designs involve assessing the potential influence of a priming stimulus on a participant's response to subsequently presented target stimuli with experimentally-manipulated qualities. In stereotype priming designs, participants view grouprelated stimuli as primes followed by target stimuli representing either stereotypes or nonstereotypes of the preceding group while responding to a task requiring them to process the targets. Stereotyping of the group can be inferred through participants' faster task RT during the stereotype condition as compared to the non-stereotype condition (Kidder et al., 2018). In this case, cognitive processing of target stimuli is facilitated (indicated by faster RT) in the stereotype condition because of the group-related priming stimulus activating stereotype content prior to its subsequent presentation as target stimuli. This automatic activation indicates implicit associations between the group and stereotypes that are assessed.

Beyond using RT as a dependent measure in stereotype priming designs, EEG measures can also be used to study stereotyping (Hehman et al., 2014; Wang et al., 2016; X. Zhang et al., 2016). The EEG method involves recording of voltage changes on the scalp, using electrodes attached to the participant's head. One specific EEG measure that has been used in previous stereotype studies is the N400 ERP component (Hehman et al., 2014; Wang et al., 2016; X. Zhang et al., 2016). The usefulness of ERPs in research has previously been described in the fields of clinical psychology (Hajcak et al., 2019) and counseling psychology (Matsen et al., 2020). ERPs are averaged segments of EEG data that were recorded across many trials of the same task condition (Luck, 2014). An ERP component refers to a pattern in the ERP data, characterizing a specific type of neural processing. The N400 ERP component reflects a 
difference in participants' neural processing between incongruent and congruent experimental conditions (Kutas \& Federmeier, 2011; Luck, 2014). N400 is characterized by a more negative (downward) deflection in the ERP waveform after presentation of stimuli incongruent with the preceding context compared to stimuli congruent with the preceding context. This waveform difference is largest over centro-parietal electrode sites and around $400 \mathrm{~ms}$ after stimulus presentation (Kutas \& Federmeier, 2011; Luck, 2014).

In the context of the stereotype priming designs discussed earlier, a more negative ERP deflection in the N400 time range in response to incongruent (non-stereotype) target stimuli than congruent (stereotype) target stimuli reflects differential processing required in the incongruent condition to activate content not primed by the preceding group-related stimulus (Hehman et al., 2014; Wang et al., 2016; X. Zhang et al., 2016). In contrast, congruent (stereotype) stimuli are in this case presumed to have been easier to process due to having been primed for activation by the preceding group-related stimulus. If during a stereotype priming experiment a counselor shows this pattern of differential processing of stereotypes versus non-stereotypes of a specific group, it may indicate an implicit tendency toward assuming the validity of group stereotypes in interactions with individuals from that group (including clients). Without conscious attention to this tendency, the counselor might unknowingly rely on stereotypes in their efforts to conceptualize and understand the traits of clients from the group. Previous N400 studies have shown neural evidence of stereotyping on the basis of gender (Wang et al., 2016; X. Zhang et al., 2016) and race (Hehman et al., 2014).

\section{Stereotyping and Biases in Counseling}

Counselors and counselors-in-training have been found to have implicit biases as measured through IATs (Boysen \& Vogel, 2008; Castillo et al., 2007; Ivers et al., 2021). Implicit 
biases and stereotyping may negatively affect the work of counselors in important ways. For example, clients who reported having experienced microaggressions from a counselor frequently noted microaggressions involving denial of stereotyping and biases or lack of awareness of these processes (Hook et al., 2016). Microaggressions are negatively associated with the clientcounselor working alliance (Owen et al., 2014). Stereotyping among counselors and counselorsin-training has been studied less frequently than implicit biases. Priming of therapists with stereotypes of Black people was subsequently associated with their assessing a fictional client as being more hostile (Abreu, 1999). The use of an explicit measure assessing a construct called Bayesian racism has recently been developed for use in the counseling field (Litam \& Balkin, 2021; Litam et al., 2022). The proposed Bayesian Racism Scale is a measure of one's belief in the rationality of discriminating based on racial stereotypes (Uhlmann et al., 2010). Researchers have suggested that counselors may use their results on this scale to reflect on their own possible tendencies toward stereotyping (Litam \& Balkin, 2021).

\section{Purpose of the Study}

In this study, we aimed to expand on existing work on implicit biases in counseling by studying stereotyping among graduate students in mental health fields with an implicit approach. We used a stereotype priming design to measure potential stereotyping tendencies in an experiment in which participants saw priming images (faces) of Black men, Black women, White men, and White women, followed by stereotypes or non-stereotypes of the primed group. Our hypothesis was that graduate students in mental health fields would show evidence of stereotyping in the priming experiment as indicated by longer task RT in response to nonstereotype words compared to stereotype words and a more negative ERP waveform in the N400 
time range in response to non-stereotype words compared to stereotype words (N400). Figure 1 illustrates the aim of the study.

\section{Method}

\section{Participants}

Participants were 33 graduate students enrolled in mental health fields. The participants included $23(69.70 \%)$ in the field of counseling, nine $(27.27 \%)$ in clinical psychology, and one $(3.03 \%)$ in social work. More specifically, $12(36.36 \%)$ of the students in counseling were master's level students in clinical mental health counseling, nine (27.27\%) were master's level students in school counseling, and two (6.06\%) were doctoral students in counselor education. All nine of the participants studying clinical psychology were doctoral students, and the one participant studying social work was a doctoral student. Ages of participants ranged from 22 to $33(M=24.61, S D=2.30)$. Twenty-eight participants identified their gender as female $(84.85 \%)$ and five as male $(15.15 \%)$. The racial backgrounds of participants were reported as White or Caucasian $(N=27,81.82 \%)$, Asian $(N=2,6.06 \%)$, Black or African American $(N=2,6.06 \%)$, and Hispanic $(N=2,6.06 \%)$.

\section{Procedure}

Participants were recruited from graduate programs at a large Southern university in the United States. The participants were recruited through flyers, emails, and in-person requests in their classes. Some participants received extra credit for participation from their course instructors. All participants received $\$ 25$ for their participation.

The experiment took place in a laboratory on a college campus. Participants read and signed an informed consent. According to the procedure approved by the institutional review board, the complete nature of the study was not described in the informed consent (stereotyping 
was not specifically discussed). Participants filled out a demographic survey and then completed the computerized experiment while EEG and RT data were collected. Afterward, participants completed additional demographic questions. Participants were fully debriefed at the conclusion of these procedures. The entire session lasted 2 hours.

\section{Measures}

\section{Stereotype Experiment}

The experiment's stimuli were pictures for primes and words for targets. The priming stimuli were 16 pictures of faces. The pictures showed four Black men, four Black women, four White men, and four White women. These stimuli were from the Face-Place Face Database (3.0), courtesy of Michael J. Tarr, Carnegie Mellon University (http://www.tarrlab.org). All face images had neutral facial expressions. The target words in the experiment were adjectives that describe people.

The experiment's target words were included based on results from a validation survey, using a sample of 69 undergraduates taking courses in educational studies. The participants received course credit for their participation. The validation survey participants rated words taken from previous literature on stereotypes of races (specifically Black and White), genders (specifically man and woman), and intersections of these races and genders. For 140 stereotype words, participants indicated which of four options_-"Black man," "Black woman," "White man," and "White woman" — was most and least associated with the word according to societal stereotypes. Participants also indicated whether each word was positive or negative in its meaning. Words related to physical appearance in the validation survey were not considered for inclusion in the experiment. This decision was made to avoid potential confounding associations between prime images and target words in the experiment. In other words, we sought words for 
the experiment that could be perceived as congruent or incongruent with each preceding prime image only on the basis of group stereotypes rather than physical features (which varied among individual prime images within the same race/gender category).

The words most often selected as "most associated" with each of the four race/gender groups by validation survey respondents and most consistently classified as either positive or negative in meaning were included in the "congruent" condition for each race/gender group in the experiment. Likewise, the words most often selected as "least associated" with each of the four race/gender groups by validation survey respondents and most consistently classified as either positive or negative in meaning were included in the "incongruent" condition for each race/gender group in the experiment. All included words showed at least $80 \%$ agreement in the validation in regard to word valence (positive or negative). The four top-rated words (two positive and two negative) were selected for each congruent and incongruent condition. When the same word was in the top four for two separate categories in the validation (i.e., congruent for one race/gender category and incongruent for another), the word was included in the condition that would produce the least drop in the agreement percentage for the condition overall. This decision was made to create distinct experimental conditions and avoid repetition effects (Grill-Spector et al., 2006).

The stereotype experiment included 512 trials across eight blocks, with each block consisting of 64 trials. An untimed rest period was given to participants after each block. In each trial, a fixation dot was first shown for $500 \mathrm{~ms}$, followed by a prime face image for $500 \mathrm{~ms}$. After a $500 \mathrm{~ms}$ interstimulus interval, a target word appeared for 1,000 ms, during which participants responded. The task was to indicate by a button press whether the word was positive or negative in meaning. The next trial began after a random interval between 1,000 and 1,200 ms (see Figure 
2). All 128 combinations of prime image and target word occurred in a random order. This randomization was executed by Neurobs Presentation (the software that ran the computerized experiment). The 128 combinations of prime image and target word were distributed across every two blocks, meaning that each combination was presented four times. One of two possible response button configurations, (1) right: negative and left: positive, or (2) right: positive and left: negative, was assigned to each participant, counterbalanced across participants. Before starting the experimental blocks, participants completed a practice block of 32 trials.

\section{EEG Acquisition and Pre-Processing}

Neurobs Presentation_(https://www.neurobs.com) was used for stimulus presentation. A Logitech F310 game controller was used as the input device, and participants used their right and left index fingers to respond. EEG data were collected using a BrainVision 32 Channel ActiChamp system (https://www.brainvision.com) with Easy Cap recording caps (Ag/AgCI electrodes). The 32 electrode locations corresponded to the international 10-20 system, and electrodes were referenced to $\mathrm{Cz}$. The data were recorded with BrainVision Recorder (electrode impedances less than $20 \mathrm{k} \Omega, 0.5 \mathrm{~Hz}-70 \mathrm{~Hz}$, and 500 samples per second). A custom MATLAB script using ERPLAB (http://erpinfo.org/erplab) and EEGLAB (https://sccn.ucsd.edu/eeglab) functions was used to analyze data. Inferential statistics were conducted using JASP (https://jaspstats.org).

Noisy channels were interpolated for individual participants, and a $60 \mathrm{~Hz}$ notch filter was applied across participants to remove electromagnetic noise in the EEG data. During analysis, the continuous EEG data were re-referenced to the average reference. The data were high-pass filtered with $0.1 \mathrm{~Hz}$ half-amplitude cutoff and low-pass filtered with $30 \mathrm{~Hz}$ half-amplitude cutoff (IIR-Butterworth, $24 \mathrm{~dB} /$ octave). The continuous EEG was segmented into epochs from $200 \mathrm{~ms}$ 
prior to the target word onset to $500 \mathrm{~ms}$ afterward. The baseline period was $200 \mathrm{~ms}$ prior to target word presentation, and all trials were corrected to baseline. Only trials with correct responses (93.9\% of trials) were included in the averaged ERPs and RTs. A moving window peak-to-peak threshold algorithm (threshold of $60 \mu \mathrm{V}$, window size of $80 \mathrm{~ms}$, and window step of $20 \mathrm{~ms}$ ) was used for artifact detection of eye blinks. A step-like artifacts algorithm (threshold of $50 \mu \mathrm{V}$, window size of $200 \mathrm{~ms}$, window step of $100 \mathrm{~ms}$ ) was used for detection of eye movements. The epochs exceeding these thresholds were excluded from ERP analysis $(M=$ $9.83 \%$ of correct trials, $S D=8.17)$.

\section{Data Analysis}

To test our hypothesis, we first calculated participants' average RT (in ms) and average N400 amplitudes (in $\mu \mathrm{V}$ ). To calculate N400, we used participants' average ERP amplitudes between 250 and $500 \mathrm{~ms}$ after target word presentation at electrodes CP1, FC1, C3, Fz, Cz, Pz, CP2, FC2, and C4. The 250-500 ms time interval has been used in previous N400 studies (Federmeier \& Kutas, 2000; Shibata et al., 2009; C. Zhang et al., 2013). The frontal, central, and parietal electrodes were selected because N400 is usually largest over the centro-parietal area (Kutas \& Federmeier, 2011; Luck, 2014), and the frontal-central and frontal electrodes (FC1, FC2, Fz) were included in previous N400 stereotyping studies (Wang et al., 2016; White et al., 2009; X. Zhang et al., 2016). Average RT and ERP values were subjected to separate prime race $($ Black, White $) \times$ prime gender $($ man, woman $) \times$ congruence $($ congruent, incongruent $)$ repeated measures ANOVAs. We reported effects and interactions involving the congruence factor as our stereotyping hypothesis was tested using this factor.

Power analysis is not possible in ERP research because the signal-to-noise ratio in ERPs (the ratio of the brain activity the researcher is trying to measure versus random variation in the 
ERP waveform) is impacted by many different factors that vary from study to study (Boudewyn et al., 2018; Luck, 2014). These factors include differences in recording quality (caused by differences in recording equipment, recording environments, and electrode impedance levels), number of trials in each condition, number of participants in each group (or in the sample as a whole if there are no groups), and characteristics of experimental stimuli that are used in different studies to measure the same ERP component (Boudewyn et al., 2018).

We had confidence in the power of the study based on previous studies showing that a within-subjects experiment with 33 participants and 512 trials has sufficient power to observe N400 (Hehman et al., 2014; Šoškić et al., 2022; White et al., 2009). We used a within-subjects design, which is common in neuroscience research (Infantolino et al., 2018). A within-subjects design increases statistical power compared to a between-subjects design as a function of the degree of correlation between repeated measures, which can result in fewer participants being needed (Cumming, 2012). The correlation between repeated measures in neuroscience studies can be large (Infantolino et al., 2018). This is understandable given the common cognitive processes required across within-subjects conditions that are designed to differ only in ways that would produce hypothesized effects. Thus, individuals' measurements often correlate due to the experimental task requiring many of the same cognitive resources across conditions (e.g., resources involved in reading a word and indicating its valence in our experiment). Statistical power is also increased through averaging ERPs from many trials together to create each participant's average ERP value for each within-subjects condition, as this reduces measurement error (Luck et al., 2021). In this study, 33 participants were presented with 64 trials per condition (64 congruent, 64 incongruent) for each of the four race/gender combinations, which is above the average number of trials per condition that Šoškić et al. (2022) reported in a review of N400 
studies. Our sample size of 33 was larger than sample sizes of many previous ERP studies that detected stereotyping effects using N400 (Hehman et al., 2014; Wang et al., 2017; White et al., 2009).

\section{Results}

\section{Reaction Time}

A race $($ Black, White $) \times$ gender $($ man, woman $) \times$ congruence (congruent, incongruent) repeated measures ANOVA was conducted on average RT (in ms). The race $\times$ gender $\times$ congruence interaction, $F(1,32)=32.27, p<.001$, and race $\times$ congruence interaction, $F(1,32)=$ $7.08, p=.012$, were both significant. The main effect of congruence, $F(1,32)=0.08, p=.775$, and the gender $\times$ congruence interaction, $F(1,32)=0.66, p=.424$, were not significant.

Post hoc tests were conducted to explore the interactions. Based on the significant race $\times$ congruence interaction, separate paired samples $t$ tests were conducted to test the effect of congruence on Black and White trials. For Black trials, there was no significant difference in RT between incongruent $(M=620.03, S D=93.55)$ and congruent $(M=612.75, S D=87.02)$ trials, $t(32)=1.90, p=.067, d=0.33$. For White trials, there was also no significant difference in RT between incongruent $(M=615.57, S D=87.67)$ and congruent $(M=621.72, S D=86.35)$ trials, $t(32)=-1.95, p=.06, d=-0.34$.

To explore the race $\times$ gender $\times$ congruence interaction, four separate two-way repeated measures ANOVAs were conducted at each level of the race and gender factors. For Black trials, there was a significant gender $\times$ congruence interaction, $F(1,32)=16.80, p<.001$, and no main effect of congruence, $F(1,32)=3.79, p=.06$. Based on the gender $\times$ congruence interaction for Black trials, separate paired samples $t$ tests were conducted to test the effect of congruence for Black man and Black woman trials. For Black man trials, average RT for incongruent target 
words $(M=630.20, S D=94.64)$ was found to be significantly longer than for congruent $(M=$ $610.24, S D=82.80), t(32)=4.32, p<.001, d=0.75$. For Black woman trials, no significant RT difference was found in average RT between incongruent $(M=609.84, S D=95.22)$ and congruent $(M=614.77, S D=94.14)$ target words, $t(32)=-.95, p=.349, d=-0.17$.

For White trials, there was a significant gender $\times$ congruence interaction, $F(1,32)=$ $16.41, p<.001$, and no effect of congruence, $F(1,32)=3.45, p=.073$. To follow up the gender $\times$ congruence interaction, separate paired samples $t$ tests were conducted to test the effect of congruence for White man and White woman trials. A significant difference was found for White man trials but in the opposite direction from what was expected, as average RT for incongruent target words $(M=606.24, S D=84.68)$ was significantly faster than for congruent $(M=628.87, S D=78.50), t(32)=-3.86, p<.001, d=-0.67$. For White woman trials, average RT for incongruent target words $(M=626.55, S D=97.69)$ was significantly longer than for congruent $(M=616.07, S D=98.44), t(32)=2.32, p=.027, d=0.40$. For woman trials, the race $\times$ congruence interaction was significant, $F(1,32)=4.89, p=.034$, and there was no effect of congruence, $F(1,32)=0.67, p=.419$. Likewise, for man trials, the race $\times$ congruence interaction was significant, $F(1,32)=32.55, p<.001$, and there was no effect of congruence, $F(1,32)=$ $0.13, p=.723$.

\section{Event-Related Potentials}

A race $($ Black, White $) \times$ gender $($ man, woman $) \times$ congruence (congruent, incongruent $)$ repeated measures ANOVA was conducted using participants' average ERP amplitudes (in $\mu \mathrm{V}$ ) between 250-500 ms after target word presentation at electrodes CP1, FC1, C3, Fz, Cz, Pz, CP2, $\mathrm{FC} 2$, and $\mathrm{C} 4$. The interaction of race $\times$ gender $\times$ congruence was significant, $F(1,32)=6.71, p=$ .014 . The effect of congruence was not significant, $F(1,32)=1.73, p=.198$, and there was no 
interaction of race $\times$ congruence, $F(1,32)=0.62, p=.438$, or gender $\times$ congruence, $F(1,32)=$ $1.01, p=.324$

To explore the interaction of race $\times$ gender $\times$ congruence, four separate two-way ANOVAs were conducted at each level of the race and gender factors. For Black trials, there was an interaction of gender $\times$ congruence, $F(1,32)=6.77, p=.014$, and no effect of congruence, $F(1,32)=0.14, p=.713$. To follow up the significant interaction, separate paired samples $t$ tests were conducted to test the effect of congruence for Black man and Black woman trials. For Black man trials, average ERP amplitude in the N400 time range for incongruent targets words $(M=-0.04, S D=1.55)$ was significantly less than for congruent $(M=0.22, S D=1.50), t(32)=-$ $2.42, p=.021, d=-0.42$. For Black woman trials, no significant difference between incongruent $(M=0.45, S D=1.76)$ and congruent $(M=0.28, S D=1.52)$ target words were found, $t(32)=$ $1.05, p=.3, d=0.18$. For White trials, no gender $\times$ congruence interaction, $F(1,32)=2.8, p=$ .104 , or effect of congruence, $F(1,32)=2.5, p=.124$, were found. Likewise, for man trials, there was no interaction of race and congruence, $F(1,32)=1.87, p=.182$, and no effect of congruence, $F(1,32)=3.38, p=.075$.

For woman trials, the interaction of race and congruence, $F(1,32)=4.1, p=.051$, approached statistical significance, and there was no effect of congruence, $F(1,32)=0.33, p=$ .568. Based on the a priori hypothesis of a stereotyping effect and the RT result indicative of stereotyping toward White women, the effect of congruence for White woman trials was tested through a paired samples $t$ test (this test for Black woman trials was reported above). For White woman trials, average ERP amplitude in the N400 time range for incongruent target words $(M=$ $-0.09, S D=1.82)$ was found to be significantly less than for congruent $(M=0.21, S D=1.76)$, $t(32)=-2.2, p=.035, d=-0.38$. Given the a priori stereotyping hypothesis, a paired samples $t$ 
test was also conducted for White man trials, though the results should be interpreted with caution given the ANOVA results. A paired samples $t$ test for White man trials showed no significant difference in ERP amplitude in the N400 time range between incongruent $(M=0.28$, $S D=1.65)$ and congruent $(M=0.31, S D=1.65)$ target words, $t(32)=-0.25, p=.802, d=-0.04$. Figure 3 depicts the average ERPs across the four race/gender conditions.

\section{Discussion}

This study explored whether graduate students in mental health fields would show neural and behavioral indicators of stereotyping in an implicit stereotype priming experiment. Our hypothesis that graduate students in mental health fields would show indicators of stereotyping was partially supported, as participants showed both behavioral (RT) and neural (N400) indicators of stereotyping toward Black men and White women. These intersectional stereotyping results extend previous studies' unidimensional stereotyping findings (Hehman et al., 2014; Wang et al., 2016; White et al., 2009). In regard to indicators of stereotyping toward Black women and White men, our hypothesis was not supported. No significant congruence effects were found for Black woman trials, and the only effect found for White man trials was a RT effect in the opposite direction from that which would indicate stereotyping.

In considering the stereotyping results, the theory of intersectional invisibility (Mohr \& Purdie-Vaughns, 2015; Purdie-Vaughns \& Eibach, 2008) may be relevant. This theory predicts that those with one subordinate group membership experience more overt forms of oppression and discrimination, while those with multiple subordinate group memberships experience more indirect forms. Due to ethnocentrism and androcentrism, a Black woman may be viewed as being an atypical woman for not being White and an atypical Black person for not being a man (Mohr \& Purdie-Vaughns, 2015). The theory is supported by previous empirical research indicating 
weaker cognitive representations of Black women compared to other groups among White participants (Phills et al., 2018; Sesko \& Biernat, 2010). Due to possible influences of intersectional invisibility in our sample of mostly White participants, learned associations between representations (images) of Black women and stereotypes of Black women may not have been strong enough to be activated through the priming technique we utilized in our experiment.

Our finding of a lack of implicit stereotyping toward White men may be a result of the societal privilege that allows for more varied representations of White men in society. This could have contributed to a sense of White man stereotypes being less predictive, thereby making them less susceptible to being activated through priming with images of faces. White man trials also showed an unexpected RT effect in the opposite direction of that which would indicate implicit stereotyping (longer RT for congruent trials). This might have been caused by differing responses to the valence judgment task between our validation sample and the sample in our experiment. We used a graduate student sample in the present study, but the validation sample was from an undergraduate population.

\section{Limitations}

This study had a number of limitations that should be considered when interpreting our results. All of our participants attended the same university in the same geographic region, which may limit generalizability to regions outside of the southern United States. Additionally, our sample size allowed us to test stereotyping effects across the sample as a whole but not test possible moderating influences of participants' own race and gender (our sample was relatively homogenous in being $81.82 \%$ White and $84.85 \%$ female). Studies that recruit larger samples or use deliberate sampling techniques (demographic inclusion/exclusion criteria) are needed to 
determine whether our observed effects might be moderated by participant demographics. In order to obtain a large enough sample we recruited students from allied helping professions outside of counseling (clinical psychology and social work) which might also limit generalizability within the counseling field specifically.

\section{Implications}

The results of this study have implications for counseling practice and research. Our results add to previous literature indicating that stereotyping and biases do exist within the counseling field (Abreu, 1999; Boysen \& Vogel, 2008; Ivers et al., 2021). We specifically found that stereotypes of Black men and White women were primed for activation by passively viewing images of faces of individuals from these groups. Counselors and counselors-in-training should consider ways in which deeply engrained cognitive associations could influence their thoughts toward and behaviors with clients from these groups. Such deliberate reflection during training experiences and during work with clients can help protect clients from harm.

The finding of a lack of implicit stereotyping effects toward Black women has implications that counselors should consider. Stereotyping is thought to reflect categorization processes through which humans generalize from previous experiences in order to quickly "make sense" of individuals (Macrae \& Bodenhausen, 2000). If intersectional invisibility results in weakened cognitive associations toward people with multiple marginalized identities (such as Black women), counselors might experience a greater sense of uncertainty or ambiguity during early stages of relationship building with multiply marginalized individuals. If this negatively impacts counselors' self-efficacy or relationship-building efforts, it could hinder their work. Counselors should therefore seek out training opportunities that accurately present information about the experiences and needs of individuals with intersecting identities. These types of 
learning experiences that address diversity through a specifically intersectional lens seem likely to increase counselors' comfort and skills in working with multiply marginalized individuals.

The observed lack of stereotyping effects toward White men could also indicate that counselors may experience initial feelings of ambiguity with this group compared to others. Counselors should attend to this possibility and strive to provide equitable services to all clients. However, we wish to make clear that our study measured cognitive processes in a controlled experiment and should not be taken as equating the complex lived experiences of Black women and White men. Possible real-world effects of our findings must be considered in the context of social systems and power structures that have historically privileged White men and oppressed Black women. Additionally, our finding of significantly longer RT for congruent than incongruent words in the White man condition is novel and deserving of future research attention more than clinical interpretation at this time. Future studies can determine if validating target words with a sample more similar to their experiment's sample or using a different experimental task (other than a valence identification task) would result in the same RT finding.

This study and its results also have important implications for counseling research. Future researchers should continue studying implicit stereotyping and biases through an intersectional lens, as we observed unique findings by taking an intersectional approach. Future studies should also determine whether participants' demographics might relate to stereotyping toward intersectional groups. Generally people show cognitive preferences for their own in-groups (Gaertner \& Dovidio, 2005), and this might affect stereotyping toward intersectional groups. Finally, we hope that this study will encourage future counseling researchers to pursue the use of neuroscience methods that can inform counseling theory and practice by providing unique information not available through self-report research methods. 


\section{References}

Abreu, J. M. (1999). Conscious and nonconscious African American stereotypes: Impact on first impression and diagnostic ratings by therapists. Journal of Consulting and Clinical Psychology, 67(3), 387-393. https://doi.org/10.1037/0022-006X.67.3.387

American Counseling Association. (2014). ACA code of ethics. https://www.counseling.org/docs/default-source/default-document-library/2014-code-ofethics-finaladdress.pdf

Boudewyn, M. A., Luck, S. J., Farrens, J. L., \& Kappenman, E. S. (2018). How many trials does it take to get a significant ERP effect? It depends. Psychophysiology, 55(6), 1-16. https://doi.org/10.1111/psyp.13049

Boysen, G. A., \& Vogel, D. L. (2008). The relationship between level of training, implicit bias, and multicultural competency among counselor trainees. Training and Education in Professional Psychology, 2(2), 103-110. https://doi.org/10.1037/1931-3918.2.2.103

Castillo, L. G., Brossart, D. F., Reyes, C. J., Conoley, C. W., \& Phoummarath, M. J. (2007). The influence of multicultural training on perceived multicultural counseling competencies and implicit racial prejudice. Journal of Multicultural Counseling and Development, 35(4), 243-254. https://doi.org/10.1002/j.2161-1912.2007.tb00064.x

Cumming, G. (2012). Understanding the new statistics: Effect sizes, confidence intervals, and meta-analysis. Routledge.

Dovidio, J. F., Kawakami, K., Johnson, C., Johnson, B., \& Howard, A. (1997). On the nature of prejudice: Automatic and controlled processes. Journal of Experimental Social Psychology, 33(5), 510-540. https://doi.org/10.1006/jesp.1997.1331

Fazio, R. H., \& Olson, M. A. (2003). Implicit measures in social cognition research: Their 
meaning and use. Annual Review of Psychology, 54(1), 297-327.

https://doi.org/10.1146/annurev.psych.54.101601.145225

Fazio, R. H., \& Towles-Schwen, T. (1999). The MODE model of attitude-behavior processes. In S. Chaiken \& Y. Trope (Eds.), Dual process theories in social psychology (pp. 97-116). Guilford.

Federmeier, K. D., \& Kutas, M. (2000). Electrophysiology reveals semantic memory use in language comprehension. Trends in Cognitive Sciences, 4(12), 463-470. https://doi.org/10.1016/S1364-6613(00)01560-6

Gaertner, S. L., \& Dovidio, J. F. (2005). Understanding and addressing contemporary racism: From aversive racism to the Common Ingroup Identity Model. Journal of Social Issues, 61(3), 615-639. https://doi.org/10.1111/j.1540-4560.2005.00424.x

Greenwald, A. G., McGhee, D. E., \& Schwartz, J. L. K. (1998). Measuring individual differences in implicit cognition: The implicit association test. Journal of Personality and Social Psychology, 74(6), 1464-1480. https://doi.org/10.1037/0022-3514.74.6.1464

Grill-Spector, K., Henson, R., \& Martin, A. (2006). Repetition and the brain: Neural models of stimulus-specific effects. Trends in Cognitive Sciences, 10(1), 14-23. https://doi.org/10.1016/j.tics.2005.11.006

Hajcak, G., Klawohn, J., \& Meyer, A. (2019). The utility of event-related potentials in clinical psychology. Annual Review of Clinical Psychology, 15, 71-95. https://doi.org/10.1146/annurev-clinpsy-050718-095457

Hehman, E., Volpert, H. I., \& Simons, R. F. (2014). The N400 as an index of racial stereotype accessibility. Social Cognitive and Affective Neuroscience, 9(4), 544-552. https://doi.org/10.1093/scan/nst018 
Hook, J. N., Farrell, J. E., Davis, D. E., DeBlaere, C., Van Tongeren, D. R., \& Utsey, S. O. (2016). Cultural humility and racial microaggressions in counseling. Journal of Counseling Psychology, 63(3), 269-277. https://doi.org/10.1037/cou0000114

Infantolino, Z. P., Luking, K. R., Sauder, C. L., Curtin, J. J., \& Hajcak, G. (2018). Robust is not neccesarily reliable: From within-subjects fMRI contrasts to between-subjects comparisons. Neuroimage, 173, 146-152. https://doi.org/10.1016/j.neuroimage.2018.02.024

Ivers, N. N., Johnson, D. A., \& Rogers, J. L. (2021). The association between implicit racial bias and mindfulness in mental health practitioners. Journal of Counseling and Development, 99(1), 11-23. https://doi.org/10.1002/jcad.12350

Kidder, C. K., White, K. R., Hinojos, M. R., Sandoval, M., \& Crites, S. L. J. (2018). Sequential stereotype priming: A meta-analysis. Personality and Social Psychology Review, 22(3), 199-227. https://doi.org/10.1177/1088868317723532

Kutas, M., \& Federmeier, K. D. (2011). Thirty years and counting: Finding meaning in the N400 component of the event related brain potential (ERP). Annual Review of Psychology, 62, 621-647. https://doi.org/10.1146/annurev.psych.093008.131123

Litam, S. D. A., \& Balkin, R. S. (2021). Assessing Bayesian Racism Scale: Measuring endorsement of racial stereotypes. International Journal for the Advancement of Counselling, 43, 504-518. https://doi.org/10.1007/s10447-021-09436-y

Litam, S. D. A., Balkin, R., \& Hendricks, L. V. (2022). Assessing worry, racism, and belief in a just world. Journal of Counseling and Development, 100(1), 75-83. https://doi.org/10.1002/jcad.12404

Luck, S. J. (2014). An introduction to the event-related potential technique (2 $2^{\text {nd }}$ ed.). MIT Press. 
Luck, S. J., Stewart, A. X., Simmons, A. M., \& Rhemtulla, M. (2021). Standardized measurement error: A universal metric of data quality for averaged event-related potentials. Psychophysiology, 58(6), 1-15. https://doi.org/10.1111/psyp.13793

Macrae, C., \& Bodenhausen, G. V. (2000). Social cognition: Thinking categorically about others. Annual Review of Psychology, 51, 93-120. https://doi.org/10.1146/annurev.psych.51.1.93

Matsen, J., Perrone-McGovern, K., \& Marmarosh, C. (2020). Using event-related potentials to explore processes of change in counseling psychology. Journal of Counseling Psychology, 67(4), 500-508. https://doi.org/10.1037/cou0000410

McConnell, A. R., \& Leibold, J. M. (2001). Relations among the implicit association test, discriminatory behavior, and explicit measures of racial attitudes. Journal of Experimental Social Psychology, 37(5), 435-442. https://doi.org/10.1006/jesp.2000.1470

Mohr, R. I., \& Purdie-Vaughns, V. (2015). Diversity within women of color: Why experiences change felt stigma. Sex Roles, 73, 391-398. https://doi.org/10.1007/s11199-015-0511-z

Owen, J., Tao, K. W., Imel, Z. E., Wampold, B. E., \& Rodolfa, E. (2014). Addressing racial and ethnic microaggressions in therapy. Professional Psychology: Research and Practice, 45(4), 283-290. https://doi.org/10.1037/a0037420

Phills, C. E., Williams, A., Wolff, J. M., Smith, A., Arnold, R., Felegy, K., \& Kuenzig, M. E. (2018). Intersecting race and gender stereotypes: Implications for group-level attitudes. Group Processes and Intergroup Relations, 21(8), 1172-1184. https://doi.org/10.1177/1368430217706742

Purdie-Vaughns, V., \& Eibach, R. P. (2008). Intersectional invisibility: The distinctive advantages and disadvantages of multiple subordinate-group identities. Sex Roles, 59, 377-391. https://doi.org/10.1007/s11199-008-9424-4 
Sesko, A. K., \& Biernat, M. (2010). Prototypes of race and gender: The invisibility of Black women. Journal of Experimental Social Psychology, 46(2), 356-360. https://doi.org/10.1016/j.jesp.2009.10.016

Shibata, H., Gyoba, J., \& Suzuki, Y. (2009). Event-related potentials during the evaluation of the appropriateness of cooperative actions. Neuroscience Letters, 452(2), 189-193. https://doi.org/10.1016/j.neulet.2009.01.042

Šoškić, A., Jovanović, V., Styles, S. J., Kappenman, E. S., \& Ković, V. (2022). How to do better N400 studies: Reproducibility, consistency and adherence to research standards in the existing literature. Neuropsychology Review, 32(3), 577-600. https://doi.org/10.1007/s11065-021-09513-4

Uhlmann, E. L., Brescoll, V. L., \& Machery, E. (2010). The motives underlying stereotype-based discrimination against members of stigmatized groups. Social Justice Research, 23(1), 116. https://doi.org/10.1007/s11211-010-0110-7

Wang, P., Yang, Y.-P., Tan, C.-H., Zhao, X.-X., Liu, Y.-H., \& Lin, C.-D. (2016). Stereotype activation is unintentional: Behavioural and event-related potenials evidence. International Journal of Psychology, 51(2), 156-162. https://doi.org/10.1002/ijop.12135

Wang, P., Yang, Y. P., Tan, C. H., Chen, Q. W., \& Cantfort, T. (2017). Gender stereotype activation versus lexical semantic activation: An ERP study. Journal of General Psychology, 144(4), 283-308. https://doi.org/10.1080/00221309.2017.1310714

White, K. R., Crites, S. L. J., Taylor, J. H., \& Corral, G. (2009). Wait, what? Assessing stereotype incongruities using the N400 ERP component. Social Cognitive and Affective Neuroscience, 4(2), 191-198. https://doi.org/10.1093/scan/nsp004

Zhang, C., Peng, G., \& Wang, W. S. Y. (2013). Achieving constancy in spoken word 
identification: Time course of talker normalization. Brain and Language, 126(2), 193202. https://doi.org/10.1016/j.bandl.2013.05.010

Zhang, X., Li, Q., Sun, S., \& Zuo, B. (2016). The time course from gender categorization to gender-stereotype activation. Social Neuroscience, 13(1), 52-60.

https://doi.org/10.1080/17470919.2016.1251965 


\section{Figure 1}

Aim of the Study in the Context of the Experimental Design

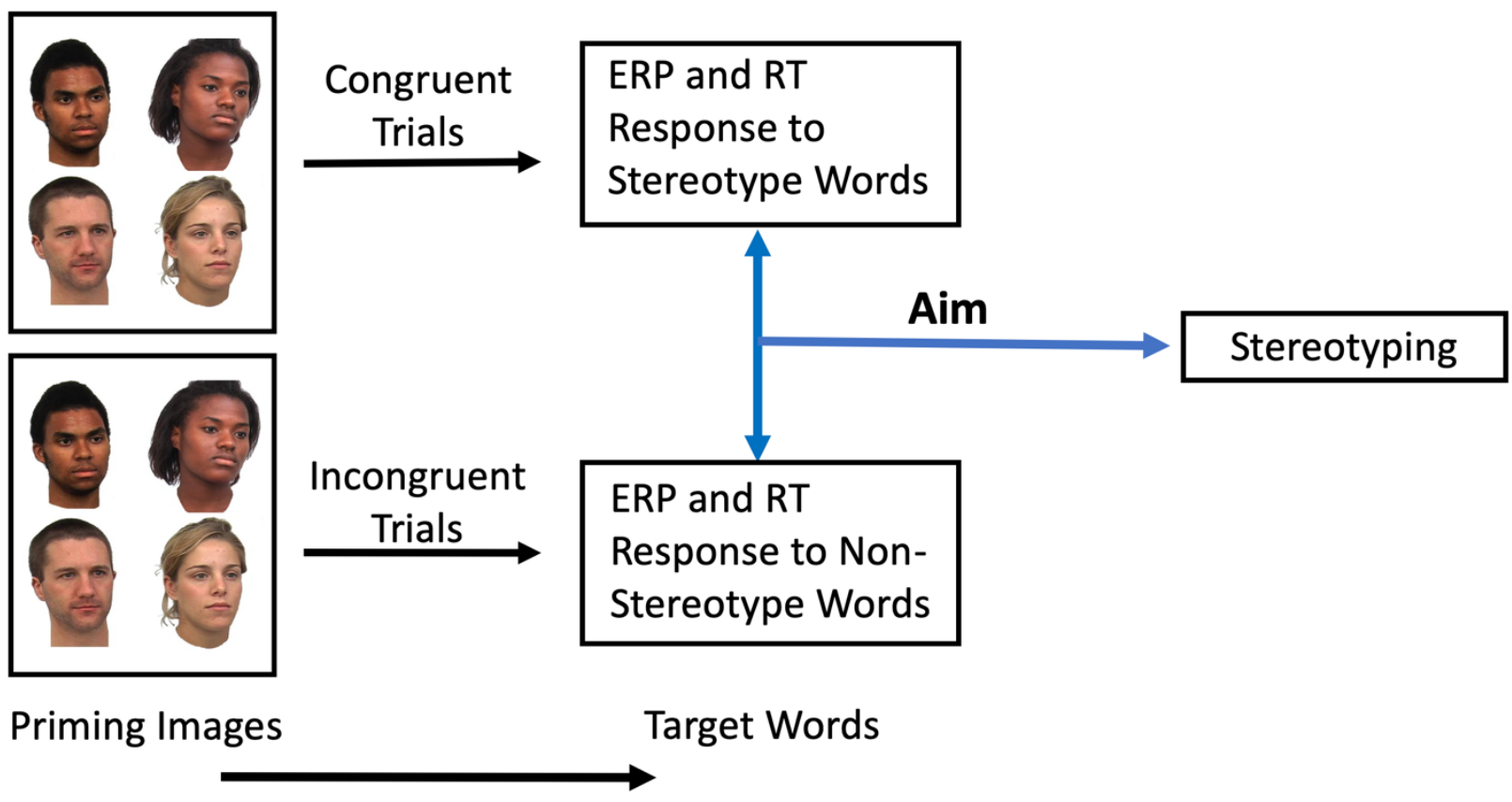

Note. $\mathrm{ERP}=$ event-related potential; $\mathrm{RT}=$ reaction time. The aim was to measure stereotyping implicitly through comparisons of ERP and RT responses to congruent (stereotype) target words versus incongruent (non-stereotype) target words following priming images.

Priming images courtesy of Michael J. Tarr, Carnegie Mellon University, http://www.tarrlab.org/ (funding provided by National Science Foundation award 0339122). 


\section{Figure 2}

Example of a Trial From the Black Man Congruent (Stereotype) Condition in the Experiment

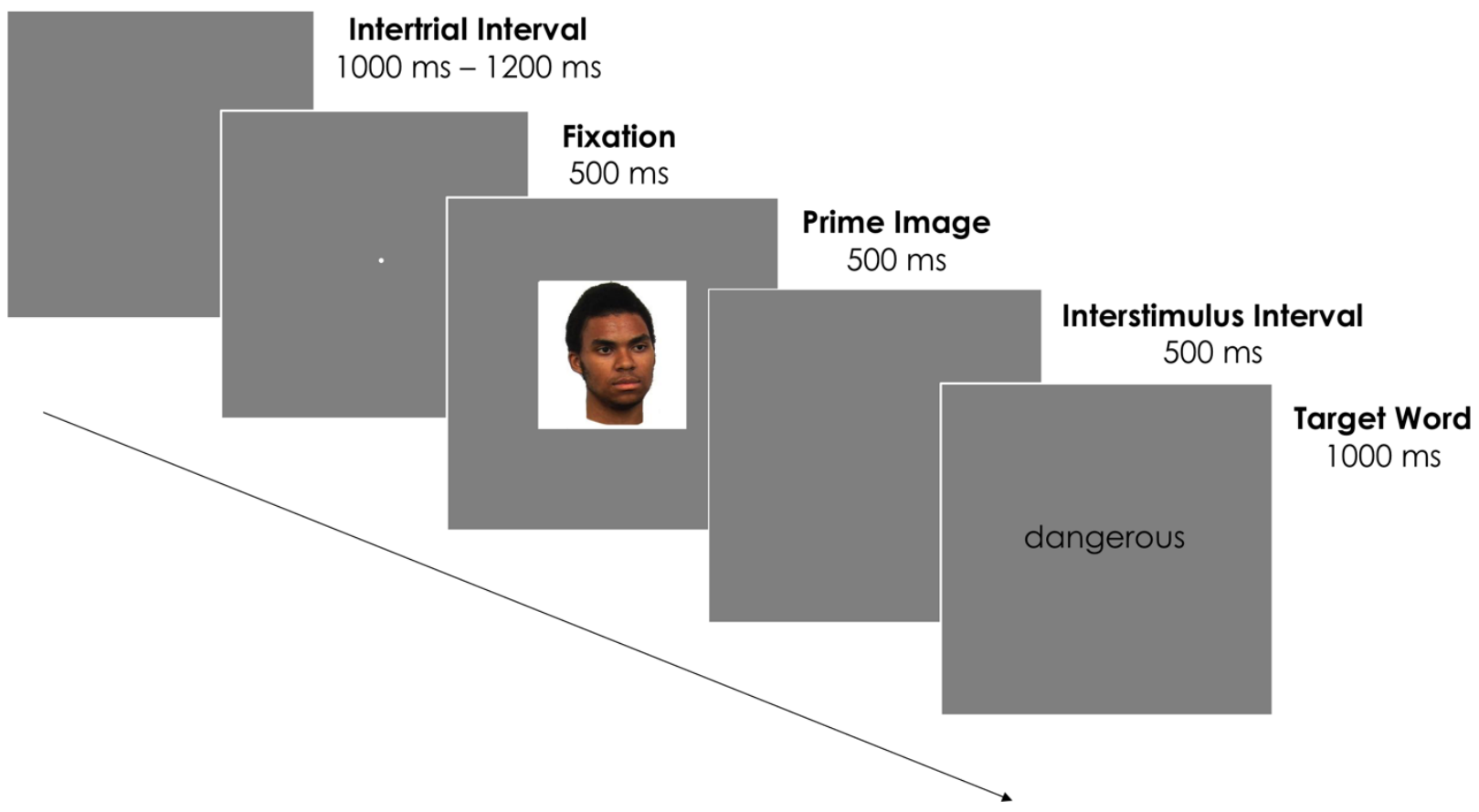

Prime image courtesy of Michael J. Tarr, Carnegie Mellon University, http://www.tarrlab.org/ (funding provided by National Science Foundation award 0339122). 


\section{Figure 3}

Event-Related Potentials Averaged Across Nine Electrode Sites (CP1, FC1, C3, Fz, Cz, Pz, CP2, FC2, and C4) in the Four Race/Gender Conditions

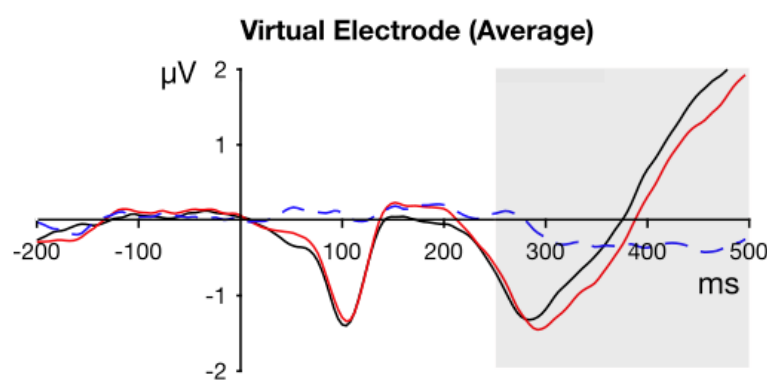

— Black Man Congruent (Stereotypes)

_ Black Man Incongruent (Non-stereotypes)

- - Incongruent - Congruent Difference

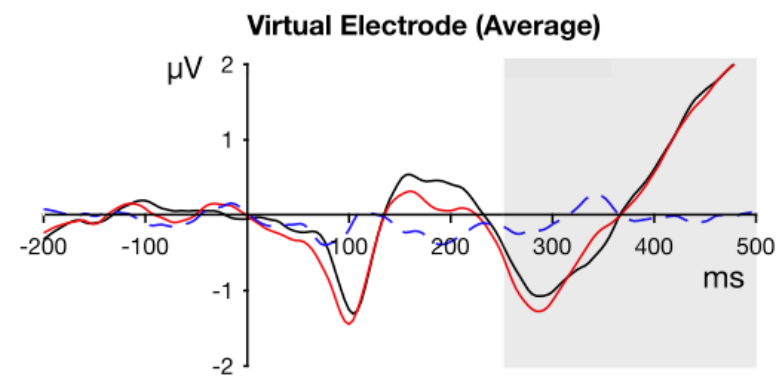

—White Man Congruent (Stereotypes)

W White Man Incongruent (Non-stereotypes)

- - Incongruent - Congruent Difference

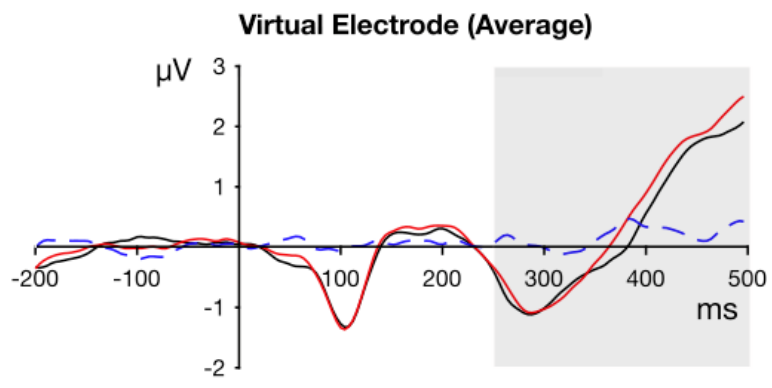

_ Black Woman Congruent (Stereotypes)

_ Black Woman Incongruent (Non-stereotypes)

- - Incongruent - Congruent Difference

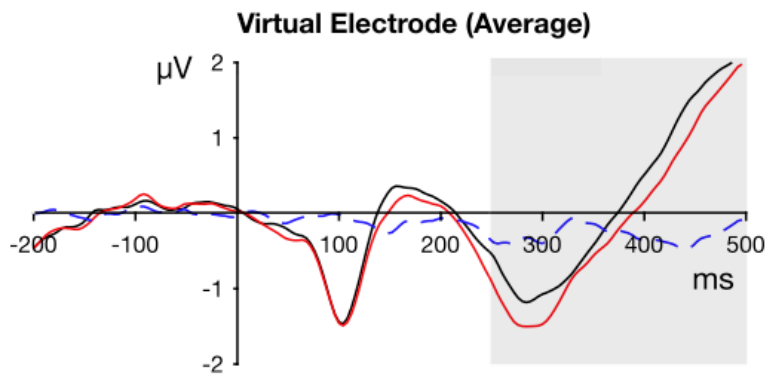

— White Woman Congruent (Stereotypes)

— White Woman Incongruent (Non-stereotypes)

- - Incongruent - Congruent Difference

Note. Zero on the $x$-axis indicates target word presentation. For each race/gender condition, the average waveforms for congruent trials, incongruent trials, and incongruent minus congruent trials (a difference wave) are depicted. The difference wave illustrates points at which the two conditions differed in voltage, with relative negativity in the incongruent condition indicated by points at which the difference wave is below zero. The $250-500 \mathrm{~ms}$ period during which we 
assessed for a statistically significant difference between incongruent and congruent conditions (N400) is shaded. 